\title{
Frihet i en liten burk? Om flexibilitet och struktur i nätbaserad undervisning
}

\author{
Helene Ehriander \& Maria Nilson
}

2016 är det tio år sedan Helene Ehriander startade den första sommarkursen vid Litteraturvetenskapliga institutionen på Växjö universitet, som idag heter Institutionen för film och litteratur vid Linnéuniversitetet. Kursen handlade om Astrid Lindgrens författarskap och blev en stor succé med flera hundra studenter från hela landet. Idag har vi erfarenheter från ett tiotal distanskurser i varierande ämnen och från tusentals studenter som gått våra sommarkurser. Vi har genom åren arbetat med ett flertal olika lärplattformar och utvecklat både kursinnehåll och en allt mer medveten nätpedagogik under årens lopp. Lärandets villkor och förutsättningar förändras ständigt, och det blir särskilt tydligt när man arbetar med nätbaserad undervisning där den tekniska utvecklingen går framåt i snabb takt. I följande artikel diskuterar vi hur vi arbetat med våra nätbaserade kurser och vilka förändringar vi gjort genom åren där vi dels gått från det mer flexibla till det mer strukturerade, dels blivit betydligt skickligare på att både aktivera studenter och på att få dem att samarbeta med varandra. Vi kommer att fokusera vår diskussion på utmaningar och motgångar, men också framgångar vad gäller att arbeta med flexibilitet och struktur i nätbaserad undervisning.

\section{Tio år med sommarkurser}

Våren 2015 var Linnéuniversitetet värd för den nationella litteraturvetarkonferens med fokus på utbildning som vartannat år hålls i Sverige. Temat för konferensen var denna gång distansundervisning och idag är det vanligt för de lärosäten som ger kurser i litteraturvetenskap att åtminstone ha någon kurs som går helt på nätet. Utbudet av distanskurser ökar men för ett flertal universitet är det först nu som den stora satsningen sker. Vissa universitet har haft en satsning på distanskurser, men tvingats att avveckla dem då de blivit alltför tidskrävande och haft för dålig genomströmning, men nu ser vi en ökning av antalet distanskurser i hela Sverige. Sedan Helene Ehriander startade den första sommarkursen om Astrid Lindgren 2006 har efterfrågan på och utbudet av distanskurser hos oss bara ökat och vi har idag fler kurser på distans än vi har på campus och sommarterminen har blivit lika stor som vår- och höstterminen.

Vad är då poängen med att ha nätbaserade kurser? En fördel för ett universitet på småländska höglandet är naturligtvis att utbildningarna kan erbjudas studenter från hela landet. Vi har etablerat oss som ett lärosäte med framgångsrika och intressanta sommarkurser, något som bidrar till att vi år efter år har ett stort antal sökande till de kurser som utlyses. Kurserna lockar inte bara studenter som har tidigare erfarenhet av litteraturvetenskap, utan många får genom kurserna sin första kontakt med ämnet.

Vi utgår ifrån ett sociokulturellt och kommunikativt perspektiv på lärande. Av stor vikt för hur lärandet går till och vilka resultat det får är i vilka kulturella omständigheter vi lever 
och lärandet sker. Således är lärandet kontextbundet. Vi uppfattar saker olika beroende på de kulturella mönster och företeelser vi är uppväxta med och som vi omges av. Vårt lärande styrs också av de kommunikativa mönster vi lärt oss att tolka utifrån ett visst perspektiv. Med andra ord är vi i vårt lärande beroende av den kultur vi omges av och att vi är kulturella varelser som hela tiden samspelar med andra människor och vår kulturella omgivning. Det benämner Roger Säljö ”sociokulturellt perspektiv” (Säljö 2010: 17). Ett annat begrepp som är centralt hos Säljö är "kulturpsykologi”. (Säljö 2010: 17) Med detta menar han att det är viktigt att intressera sig för hur individer och grupper tillägnar sig och utnyttjar fysiska och kognitiva resurser. I denna aspekt är samspelet mellan kollektiv och individ i fokus.

Säljö menar vidare, och då hänvisar han till Vygotsky, att redskapen och verktygen är väsentliga när man betraktar lärande ur sociokulturella aspekter. (Säljö 2010: 20). När vi tillägnar oss de resurser vi behöver för att kunna bli delaktiga i den interaktion som eftersträvas för positiv inlärning behöver studenterna kunna använda redskapen, greppa verktygen och kunna interagera med andra. Det finns många som av sociokulturella och kulturpsykologiska anledningar utesluts av den tradition som bestämt hur denna kultur ska se ut. Vi arbetar ständigt med frågan hur vi ska kunna underlätta för så många som möjligt att bli en del av vår utbildningsmiljö, naturligtvis utan att sänka kraven eller tulla på kvaliteten. Säljö skriver att det är genom kommunikation som sociokulturella resurser skapas och förs vidare. För att lärandet ska bli så bra och effektivt som möjligt krävs att de interagerande delar idéer, värderingar, kunskaper, artefakter och sätt att kommunicera. Säljö skriver vidare att handlingar och kunskaper måste utifrån ett sociokulturellt perspektiv "relateras till sammanhang och verksamheter”. (Säljö 2005: 130) Detta är en viktig aspekt och vi som arbetar med både vårt eget livslånga lärande och att underlätta för andra personers lärande måste ta de sociokulturella aspekterna i beaktande både då vi försöker konstruera en lyckad plattform för lärande och då vi ibland måste analysera varför ett lärande inte fick önskade resultat.

\section{Från First Class till MyMoodle}

Naturligtvis kräver en nätbaserad kurs att involverade lärare skaffar sig kunskap om och utnyttjar de tekniska resurser och verktyg som vi idag har till vårt förfogande. Samtidigt har idag alla LNUs kurser, även de som går på campus, en lärplattform som både undervisande lärare och studenter kan använda men det är sällan dessa utnyttjas fullt ut. Under dessa tio år med sommarkurserna, då vi gått från lärplattformar som First Class, via Moodle till dagens MyMoodle, har en snabb utveckling skett och vi har idag tillgång till tekniska lösningar som inte var tillgängliga när vi startade. Samtidigt är verktyg just verktyg. I Med hög kvalitet på nätet. En handbok i nätbaserad undervisning för universitetslärare påpekar Löfström et al att: ”Informations- och kommunikationstekniken i sig gör inte undervisningen kvalitativ och den hjälper inte heller de studerande som sådan att lära sig” (Löfström et al 2007: 12). En viktig erfarenhet är att verktyg både måste testas och finslipas för att verkligen vara till nytta.

Nya medier och teknologi gör det möjligt att genomföra undervisning på flera olika sätt och använda olika undervisningsmaterial. Samtidigt kan dessa metoder från individens synvinkel vara kognitivt belastande, vilket stör inlärningen. Vid planering och genomförande av nätbaserad undervisning är det alltså viktigt att planeringen, lärarens och den studerandes 
verksamhet samt funktioner för informationsbehandling beaktas som en helhet (Löfström et al 2007: 15).

Även om lärplattformen i sig blivit bättre och bättre har det varit ett stressmoment att tvingas byta med jämna mellanrum och det har aldrig varit vi som pedagoger som initierat varken ett byte eller en uppgradering, vilka samtidigt naturligtvis varit nödvändiga. Ett dilemma vi diskuterat en hel del inom lärarlaget är att det inte alltid känns som om vi pedagoger blir involverade eller ens tillfrågade när en lärplattform ska uppgraderas och att samarbetet mellan lärare, IKT-pedagoger och IT-support behöver utvecklas Detta måste också få vara ett samarbete som får ta tid.

Vi har idag betydligt fler möjligheter till kompetensutveckling för undervisande lärare inom IKT-pedagogik och även här finns mer att göra. Dels behöver naturligtvis lärare tid till denna kompetensutveckling, en tid som inte alltid finns, dels vore det en fördel om det blev tydligt meriterande att ha gått kurser inriktade på distans-undervisning vid exempelvis tjänstetillsättningar. Samtidigt som utbudet av utbildningsmöjligheter ökar, ser vi också ett större behov av vägledning för den enskilda läraren så att hen får den kompetensutbildning hen behöver.

\section{Handbokens betydelse}

Under vårt förändringsarbete med sommarkurserna har en hel del fokus legat på just introduktionen och vi har diskuterat hur vi ska få fram den nödvändiga informationen till studenterna vad gäller såväl kursens innehåll som hur lärplattformen ska kunna användas på bästa sätt. Vi har lagt mycket tid på att skapa en handbok vars innehåll är allmänt för samtliga sommarkurser och kurspecifikt för den kurs studenten ska läsa. Handboken innehåller dels sådant som alla studenter vid Linnéuniversitetet bör känna till, dels en studieguide för den enskilda kursen. Det är mycket information som trängs i denna guide och studenterna föredrar många gånger att hellre använda de frågeforum som finns på plattformen än att ta till sig den utlagda informationen. För att minimera antalet frågor, som redan är besvarade, ligger numera handboken med studieguiden först i kursrummet och det är det första dokument som studenterna möter. Dessutom kompletteras numera den skrivna handboken med inspelade föreläsningar för att underlätta introduktionen och för att tillgodose studenternas olika lärstilar.

I sin utvärdering av Linnéuniversitetets distansundervisning menar Creelman och Reneland-Forsman bland annat att introduktionen är av högsta vikt (Creelman \& RenelandForsman 2012). Det går inte att sticka under stol med att genomströmningen är lägre på distanskurser än på campuskurser, något som naturligtvis kan bli ett ekonomiskt dilemma och vi vet idag att det är lätt att tappa studenter de första veckorna på en kurs. För att undvika detta behövs inte bara tydlig och lättöverskådlig information om kursupplägg och examination. Det behövs också närvarande lärare och fungerande teknik som är lättbegriplig för studenterna. Vi har som mål att svara på frågor och kommentera inlägg så fort som möjligt. 
En poäng med en tydlig introduktion är också att synliggöra kursens upplägg och mål. Hattie menar att: "Visible teaching and learning occurs when learning is the explicit and transparent goal, when it's appropriately challenging, and when the teacher and the student both (in their various ways) seek to ascertain whether and to what degree the challenging goal is attained" (Hattie 2012: 18). Vi strävar också efter att i examinationsuppgifterna tydligt synliggöra kursmålen.

Idag diskuteras ”digital literacy” som ett alltmer viktigt begrepp. Då mycket av både vår kommunikation och vårt kunskapssökande sker på nätet är det väsentligt att utveckla en förmåga att hantera allt från Wikipedia till sociala medier och hur asynkron kommunikation på kursplattformarna ska föras för att inte bli till missförstådd och kanske såra en kurskamrat eftersom text många gånger kan låta hårdare än en hastigt fälld replik där kroppsspråk och miner understryker att det handlar om ett skämt. För att underlätta studenters lärande behöver vi också låta dem utveckla sin "digital literacy" och detta måste vara en del av kursens upplägg då det är lätt för studenterna att tro att eftersom kursen finns på nätet så går det också att plocka information från allehanda källor som ligger ute på internet. Doug Belshaw skriver i sin avhandling om "digital literacy":

Digital literacies are transient: they change over time, may involve using different tools or developing different habits of mind, and almost always depend on the context in which an individual finds herself. They can be scaffolded and developed but to do so, involves more than training, it involves education. Digital literacies cannot be developed in one - off contextualized half-day workshop (Belshaw 2012: 204).

Det är lätt att falla $\mathrm{i}$ fällan och tro att dagens studenter behärskar allt från informationssökning på nätet, till hur man chattar eller hur man laddar upp ett fotografi på sin profil. Det är förvånansvärt många studenter som står lika handfallna inför tekniken som deras medelålders lärare och vikten av tydlig information och relevanta hjälpmedel är stor. Om tekniken krånglar, och det kan då handla om allt från att det inte går att logga in på lärplattformen till att det är svårt att hantera olika diskussionsforum, att det är krångligt att hitta e-böcker eller att chatten hela tiden hakar upp sig, förlorar vi de studenter som känner sig osäkra. Edmunds och Conole diskuterar i en artikel vad de kallar för: TAM - Technology Acceptance Model. Det krävs en viss acceptans inför och erfarenhet av de tekniska lösningar vi använder oss av (Edmunds \& Conole 2012). Idag har vi betydligt mer information av detta slag i kursernas handböcker, dels för att vi insett att det behövs, dels för att våra tillgängliga verktyg blivit mer avancerade och kräver mer av både undervisande lärare och studenter.

Tekniken är naturligtvis endast en liten del av nätundervisning, men det är en viktig del och vi lägger ibland blygsamt med tid på att utveckla och finslipa vad som skulle kunna bli hjälpsamma pedagogiska verktyg. Avriam och Eshet-Alkalai menar att:

It is possible to help students acquire skills in two ways: directly, by developing courses in the relevant skills, or indirectly, by designing the learning environments or the curriculum in such a way that the necessary skills are acquired 'naturally' while acting and learning in the environment for other purposes [...] (Avriam \& Eshet-Alkalai 2006).

Även om våra kursmål inte innehåller något om att utveckla en digital kompetens hos våra studenter är det nödvändigt att vi arbetar med det. 


\section{Vilka studenter har vi och vad behöver de?}

Betydelsen av att redan från början veta vilka studenter som ska gå en kurs och vilka förkunskaper de har går naturligtvis inte att underskatta. Elmgren och Henriksson skriver i Universitetspedagogik om vikten av att "bygga undervisningen med hänsyn till studenternas förförståelse” (Elmgren \& Henriksson 2010: 51), vilket kan jämföras med Conole som skriver: "Understanding the nature of your learners, their competences, aspirations and perceptions is important and need to feed into the designprocess" (Conole 2015: 4). Hur hanterar man då detta på en nätbaserad kurs med tvåhundra studenter? Våra studentgrupper på dessa kurser är påfallande heterogena och många är de studenter som ägnar sig åt det som kallas livslångt lärande och som innebär en stark relation mellan kunskap och yrkesutövande. Vi har ett stort antal yrkesverksamma lärare och bibliotekarier som läser sommarkurserna som fortbildning, vi har ett flertal litteraturstudenter som återkommer år efter år och vi har en hel del studenter som aldrig läst vid universitetet tidigare och som nu vill försöka sig på högre studier eftersom de är intresserade av ämnet. Detta är naturligtvis en utmaning på många sätt, men samtidigt finns det hos alla studenter ett gediget intresse för det kursen erbjuder, exempelvis fantasylitteratur, Harry Potter och hans världar, romancelitteratur och Astrid Lindgrens författarskap, vilket underlättar och svetsar samman studenterna.

Staffan Selander och Gunther Kress använder begreppet "didaktisk design” för hur man kan skapa och forma förutsättningar för lärande och för hur individen ska kunna återskapa informationen i egna meningsskapande processer. Att tänka i termen "design för lärande” innebär att se undervisande lärare som en "designer” av undervisningen genom planering, genomförande, användande av kursrummet och de olika resurserna samt på det sätt på vilket kursen avslutningsvis utvärderas (Selander \& Kress, 2017: 24). ”Design kan också förstås ur ett maktperspektiv, där de som har förfogande över resurser använder dessa för att designa något för någon annan” (Selander \& Kress: 24f) men samtidigt kan också kritik utvecklas gentemot dem som har kontroll över resurserna (Selander \& Kress: 25). Man kan också se till en annan delaspekt, nämligen "design i lärande” där lärandet för den enskilde ses som ett meningsfullt sätt att utvidga sin repertoar för att "förstå och handla i ett meningsfullt sammanhang” (Selander \& Kress: 25). Därmed är vi inne på det som är grunden för våra kurser, nämligen lärande som kommunikation och hur den information i form av kursmaterial, kurslitteratur, föreläsningar, chattar, frågelådor och kontakt med lärare och andra studenter transformeras till kunskap. När vi designar våra kurser gör vi det med tanke på den heterogena studentgruppen och erbjuder flera möjliga val och vägar för studenterna att både utvidga sin repertoar och att transformera informationen så att de skapar nya representationer i den enskilda studentens specifika sammanhang. Lärandet ska med andra ord både ge den fördjupade kunskap studenten efterfrågar utifrån sitt sammanhang och erbjuda ett breddat perspektiv på det ämne kursen behandlar.

Det första steget är att så fort kursen öppnar identifiera vilka studenter som sökt sig till sommarens kurs. Inledningsvis behövs en så kallad isbrytaraktivitet som också fungerar som igångsättare för studenterna och som gör att vi börjar lära känna dem. Vi har under alla år inlett kurserna med att både lärare och studenter fått presentera sig och presentationen ska vara knuten till kursens ämne så att studenterna genast får kontakt med andra studenter, kommer igång att börja använda lärplattformen och får fokus på kursinnehållet. På kurserna 
ingår också synkrona introduktionschattar där det finns möjlighet att ställa frågor och knyta kontakter. Det kan tyckas självklart, men är samtidigt väl värt att påpeka, hur viktigt det är att en lärare "bjuder lite på sig själv" i sin presentation, att studenterna någon gång blir sedda som individer och att de i alla fall på något plan lär känna undervisande lärare. Vi lägger ofta mycket tid på att svara på alla studentpresentationer så att studenterna ska känna sig välkomna och förstå att de är betydelsefulla och att de berikar kursen med sina inlägg och sin kompetens.

Sommarkurserna bygger med få undantag på undervisande lärares egen forskning, vilket naturligtvis gör det lättare att visa studenterna att vi brinner för ämnet. Martin Stigmar skriver i "Att utvecklas som universitetslärare” om vikten av att vara entusiastisk inför sitt ämne för att kunna fånga studenternas intresse (Stigmar 2009: 33). John Hattie i sin tur påpekar att en framgångsrik lärare inte bara måste älska sitt ämne, utan också behöver älska att undervisa och vara öppen för att gemensamt lära sig av och växa tillsammans med sina studenter. Framgång, menar han:

[...] requires a love of the content, an ethical caring stance deriving from the desire to instill in others a liking or even love of the discipline being taught, and a demonstration that the teacher is not only teaching, but also learning (Hattie 2012:20).

För att möjliggöra både mer student-till-student-interaktion och mer student-till-lärareinteraktion har vi under de senaste åren arbetat om upplägget på våra sommarkurser, vilket diskuteras nedan

\section{Från paperuppgift till flera mindre uppgifter}

När sommarkurserna startade examinerade vi studenterna genom att de skrev ett avslutande paper. Vi valde att låta studenternas examinationsuppgift vara ett paper på ungefär 10-12 sidor där studenterna kunde välja ämne och infallsvinkel beroende på vad de var intresserade av och inom vilket yrke de hade behov av att meritera sig. Tanken var att ge yrkesverksamma studenter spjutspetskompetens inför framtiden och studenter som ännu inte kommit ut i yrkeslivet en möjlighet att profilera sig med en tyngre merit. Studenterna hade, förutom både skrivna och inspelade föreläsningar, också tillgång till handledning och under ett par år fick vi in ett ansenligt antal både välskrivna och intressanta paper från studenter.

Under dessa år skapades tre antologier som dels innehöll artiklar skrivna av forskarkolleger, dels paper som studenter lämnat in och som de fick möjlighet att arbeta vidare på fram till publiceringsbar artikel. 2011 utgavs Starkast $i$ världen. Att arbeta med Astrid Lindgrens författarskap i skolan på BTJ Förlag. 2012 utgavs Ett trollspö på katedern. Att arbeta med fantasy i skolan också den på BTJ Förlag och 2013 kom antologin Chick lit. Brokiga läsningar och didaktiska utmaningar på Liber Förlag. En tanke med att ha paperuppgift som examinationsform var sålunda redan från början att ge några av våra ambitiösa studenter en möjlighet att bli publicerade och att därmed också ge dem en hållbar merit inför framtida arbeten.

Samtidigt som vi fick in en del riktigt bra paper, fanns det nackdelar med detta upplägg. Det gynnande de erfarna studenterna med tidigare universitetsstudier bakom sig, de som redan lärt sig akademiskt skrivande och att strukturera upp sin tid för att kunna möta 
deadlines. Studenter som precis startat sin utbildning hade svårt både att klara av att skriva en längre vetenskaplig text och att hantera sådant som referenser och litteraturförteckningar. Det fanns också många som upplevde det som svårt att överblicka litteraturlistan, läsa in kurslitteraturen och koppla denna till uppgiften på ett relevant sätt. Vi som undervisade på kurserna började uppleva att den avslutande tentamensrättningen började bli ohanterlig och mycket tidskrävande och studenternas utvärderingar visade att ett flertal av dem ville att examinationen skulle delas upp och ske löpande under kursen.

I dag har vi en löpande examination där de flesta av kurserna har en introduktionsuppgift med deadline tre till fyra veckor in på sommarterminen. Tanken med detta har varit att leda in studenterna från en mindre uppgift till en större och att på så sätt ha en tydligare progression i kurserna. Vi ger tämligen rikligt med feedback på studenternas introduktionsuppgift för att de under kursens gång ska kunna bättra på sitt skrivande och en del av bedömningen av slutexaminationen blir naturligtvis att se om studenterna använt sig av den feedback de fått. Ett ständigt återkommande problem är att många studenter inte läser kurslitteraturen ordentligt och på flera av kurserna finns nu betydligt mer riktade frågor i examinationen som gör att studenterna precis förstår vad de förväntas läsa inför varje delmoment för att bli godkända, utan att vi för den skull efterfrågar faktakunskaper utan reflektion och eftertanke. För undervisande lärare är detta upplägg en fördel då det varit stressigt och tungt att rätta allt i augusti, och för studenterna är det också en fördel då de kan få sina resultat inrapporterade tidigare eftersom rättningen går fortare med en kortare slutuppgift.

\section{Lärarlag}

Att undervisa vid universitetet har traditionellt sätt varit ett ensamt arbete. Samtidigt vet vi att det finns oerhörda fördelar med att samarbeta, både för läraren och för studenten. Vår starkaste erfarenhet är att det blir både lättare och bättre i lärarlag.

Planning can be done in many ways, but the most powerful is when teachers work together to develop plans, develop common understanding of what is worth teaching, collaborate on understanding of what is worth teaching, collaborate on understanding their beliefs of challenge and progress and work together to evaluate the impact on student outcomes (Hattie 2012: 41).

Vi lärare får "draghjälp” och stöd av varandra och kan då bättre stödja studenterna. Att vi behöver fler och bättre stödstrukturer för våra studenter är uppenbart och detta behövs både på campuskurser och på distanskurser. Vi arbetar hela tiden med att hitta den design för lärande som leder studenterna framåt genom en transformationsprocess, som uppmuntrar lärande genom socialt samspel och som möjliggör för studenter med olika sociokulturell bakgrund att utveckla nya representationer inom ramarna för de olika kurserna. Vi försöker undvika att falla i fällan att allt för gymnasielikt leda våra studenter till kursmålen, och även om det finns studenter som inledningsvis behöver mycket stöd är det vårt mål att hjälpa dem mot självständighet, uppmuntra deras kritiska förmåga och stimulera egna val så att utbildningen på flera plan kan vara till nytta och glädje för studenterna när det gäller deras yrkesutövning, framtida studier eller som en del av deras bildning. 


\section{Referenser}

Avriam, Aharon \& Yoram Eshet-Alkalai (2006), “Towards a theory of digital literacy: three scenarios for the next steeps”, i European Journal of Open, Distans and E-Learning, nr. 1. Opaginerad. [20160607]

Belshaw, Douglas, (2012), What is 'digital literacy'? A pragmatic investigation. Doctoral thesis, Durham University.

Conole, Gráinne (2015), The 7Cs of Learning Design. University of Leicester, http://www2.le.ac.uk/projects/oer/oers/beyond-distance-research-alliance/7Cs-toolkit [20160407]

Coomey, Marion \& John Stephenson (2001), “Online Learning: It is All About Dialogue, Involvment, Support and Control - According to Research”, i Teaching and Learning Online: Pedagogies for New Technologies, s. 37 - 52. [20160709]

Creelman, Alastair \& Linda Reneland-Forsman (2012), Genomlysning av distansverksamheten vid Linnéuniversitetet, https://medarbetare.lnu.se/social/groups /natbaserat-larande-digitalt-campus/posts/224 [20140608]

Edmunds, Rob, Mary Thorpe \& Grainne Conole (2012), "Student attitudes towards and use of ICT in course study, work and social activity: a technology acceptance model approach”, British Journal of Educational Technology, vol. 43, no. 1, s.71 - 84. [20160605]

Elmgren, Maja \& Ann-Sofie Håkansson (2010), Universitetspedagogik. Stockholm: Norstedts.

Hattie, John (2012), Visible Learning for Teachers. Maximizing Impact on Learning. New York/London: Routledge.

Löfström, Erika, Kaisa Kanerva, Leena Tuuttila, Anu Lehtinen \& Anne Neugi (2010), Med hög kvalitet på nätet. En handbok i nätbaserad undervisning för universitetslärare. Helsingsfors universitets förvaltningspublikationer. Rapporter och utredningar, nr. 72. [20160608]

Schreus, Bert, Antoine van den Beemt, Fleur R. Prinsen, Gabi Witthaus, Grainne Conole \& Marten De Laat (2014), “An investigation into social learning activities by practioners in open educational practices", The International Review of Research in Open and Distance Learning, vol. 15, no. 4. Opaginerad. [20160609]

Selander, Staffan \& Gunther Kress (2017), Design för lärande - ett multimodalt perspektiv. Lund: Studentlitteratur.

Simpson, Ormond (2008), "Motivating learners in open and distance learning: do we need a new theory of learner support?", Open Learning. The Journal of Open and Distance Learning, Routledge, 23:3, s.159-170. [20160608]

Stigmar, Martin, (2009), "Att utvecklas som universitetslärare”, i Martin Stigmar (red.), Högskolepedagogik. Att vara professionell som lärare i högskolan. Stockholm: Liber, s. 32-44.

Säljö, Roger (2010), Lärande i praktiken. Stockholm: Norstedts. 